\title{
THERAPEUTIC APPLICATION OF CALF THYMUS EXTRACT (TFX)
}

\author{
ALEKSANDER B. SKOTNICKI \\ Department of Hematology, Cracow Academy of Medicine, Kopernika 17, 31-501 Cracow, Poland
}

\begin{abstract}
The semipurified calf thymus extract, TFX, produced since 1973 by the Polish Pharmaceutical Industry (POLFA) has been found to exert biological activities meeting criteria for thymic hormones. During the last 15 yr TFX has been evaluated independently by several Polish medical centers in over 1000 patients with symptomatically different but pathogenically similar human diseases, including primary immunodeficient states, bone marrow failure, autoimmune disorders, chronic skin diseases, recurrent viral and bacterial infectious diseases and some oncological disorders. Long term immunotherapy with TFX - expressing the pro-host approach - resulted, in the majority of the observed patients, in amelioration of symptoms and signs of the disease and in parallel normalization of disturbed immune parameters. It is suggested that IFX (and perhaps other thymic hormones) would support, modify and enrich future treatment protocols, especially in patients with immunodeficiency-related or chronic immune-mediated diseases.
\end{abstract}

Key words: Thymic extract, Immunomodulation, Immunodeficiency-related and immune-mediated human diseases.

\section{INTRODUCTION}

Thymic factor $\mathrm{X}$ (TFX) is an aqueous extract from juvenile calf thymuses. The purification procedure employs the Polfa Pharmaceutical patented method involving ammonium sulphate fractionation, desalting through a G-25 porosity molecular sieve and ionexchange chromatography. TFX is a nucleotide- and lipid-free polypeptide mixture, with a major component of mol. wt 4200 , accompanied by traces of several other fractions with mol. wts ranging from 2000 to about 18,000 , which can be detected by $10 \%$ polyacrylamide gel electrophoresis at $\mathrm{pH} 6.8 .^{1,2}$

During the last $15 \mathrm{yr}$ TFX has been tested in several assays designed for studying thymus-derived products. Investigations included the effect of TFX on both T-cell markers and proliferative capacity, as well as the effect on T-cell effector functions.

The biological activities of TFX found in both in vitro and in vivo studies have been published in previous papers. ${ }^{3-8}$ In this discussion the results of clinical studies performed with TFX during the last $15 \mathrm{yr}$ in selected groups of patients will be summarized.

\section{PATIENTS WITH LEUCOPENIA}

The rationale for clinical trials with TFX in patients demonstrating various degrees of bone marrow failure was based on experimental data showing the relationship between thymus humoral function and hemopoiesis, ${ }^{9-11}$ as well as the in vitro effect of TFX on mouse and human myelopoiesis. $^{12-17}$

To test the TFX effect on depressed leucopoiesis several clinical trials were performed with a total of 123 published cases including patients with primary aplastic anaemia, myelodysplastic syndrome and secondary leucopenia or pancytopenia due to bone marrow toxic agents (antibiotics, anticonvulsants, antiarthritics, antithyroids, cytostatics, irradiation).

The administration of TFX resulted in $60-70 \%$ of the cases in accelerated recovery of bone marrow iatrogenic damage, with normalization of peripheral blood counts, and in counteraction of the potentially myelosuppressive side effects of irradiation as compared to a control group with no TFX. Generally, the increased granulocyte, lymphocyte, reticulocyte and erythrocyte counts were followed by a rise in platelet levels. A follow-up evaluation of the bone marrow picture showed in the majority of cases an increased cellularity and maturation of blood cell precursors even in patients previously refractory to several weeks or months of conventional myelotrophic treatment. ${ }^{8,18-20}$ 


\section{ADULT PATIENTS WITH CHRONIC RECURRENT UPPER RESPIRATORY TRACT INFECTIONS}

A group of 26 patients (aged 21-55 yr) with recurrent infections were chosen for the immunorestorative trial with TFX. These subjects suffered from eight to ten episodes of severe infections per year, each lasting from 14 to 21 days and were resistant - in terms of natural history of the disease - to antibiotics, vaccinations, inhalations and climate treatment. In some of the patients the recurrent infections were followed by the development of rheumatoid arthritis, bacterial endocarditis, spastic bronchitis and severe otitis. In 20 cases out of the above group quantitative and/or functional changes in the T-lymphocyte compartment of the immune system were found.

As they had not improved under conventional treatment and the $\mathrm{T}$-cell defect was considered to be pathogenetically related to the development of the disease, immunotherapy with TFX was initiated. The patients were observed for 12 months, receiving the drug daily for 1 month and every second day thereafter.

In $70 \%$ of patients the TFX application resulted in lowered frequency of infection episodes and, in all cases, in shortening the time (mean $=3$ days) and diminishing the severity of recurrences. The occurring infections were of similar character to those observed prior to immunotherapy with TFX but required less or no antibiotics. In none of the cases did the infection episodes trigger the development of postinfection complications, as was seen in some patients before immunotherapy.

The clinical improvement correlated with an immunoreconstructive influence of TFX on T-cell number and function. The authors concluded that administration of TFX in patients with recurrent infections of the upper respiratory tract can be considered as causative therapeutic approach and in the light of high effectiveness in changing the natural course of the disease - as a treatment of choice. $^{21}$

In another group of 162 patients with chronic spastic bronchitis, aged 43-72 yr (mean 52 yr) and receiving encortolon (4-12 $\mathrm{mg}$ daily), an attempt was made to counteract its granulocyte suppression side effect, by administration of TFX (two times per week) for 1 year in $50 \%$ of the subjects.

It was found that association of steroid therapy with TFX injections caused normalization of decreased granulocyte phagocytic activity (for neutral latex particles and Staphylococcus aureus). On the other hand, granulocyte migration tested both in vivo and in vitro remained defective in both groups.
It was observed that the combined steroid-TFX treatment resulted in better clinical response with less exacerbation of pulmonary disease than in the steroid group. ${ }^{22}$

The above observations correspond with previous in vitro data showing the effect of TFX on granulocyte and macrophage phagocytic capacity. ${ }^{23-26}$

\section{CHILDREN WITH RECURRENT INFECTIONS OF THE RESPIRATORY TRACT}

The placebo-controlled trial was performed in 53 children suffering from chronic bronchitis which had lasted for at least 9 months, with frequent recurrences occurring once or twice per 2 months. The above group of patients, aged from 19 months to $10 \mathrm{yr}$ (mean $=4.4 \mathrm{yr})$, received for $1-2$ months TFX (ten cases), levamisole ( 23 cases) or were observed without administration of any immunomodulators (20 cases). Their clinical and immunological status was monitored for 9 months following termination of the course of immunoenhancing therapy. In both of the treated groups, on comparing to the control one, statistically significantly fewer episodes of upper respiratory tract infection were observed and occurrences were milder, of shorter duration and required no or less antibiotics than before TFX application. Simultaneously, a tendency for normalization of the previously disturbed number and function of T-lymphocytes was found. ${ }^{27}$

\section{PATIENTS WITH RECURRENT HERPES SIMPLEX LABIALIS INFECTIONS}

Eight patients, aged $18-35 \mathrm{yr}$, with a past history of several years recurrent herpes labialis infections, ranging from five to ten per year, received TFX for a period of at least 12 months duration. TFX was administered every second day for the first month and two times weekly thereafter. In some of the patients TFX was injected 'on demand' during the prodromal period which generally preceded the appearance of herpes vesicles, i.e. when the subject experienced burning, itching, tingling or numbness in the skin around the mouth. Two of the observed cases also received TFX before exposure to spring sunlight during skiing, as this had previously been followed by HSV reactivation.

Clinical assessment was based on the annual recurrence rate, duration of ocurrences, extension of the vesicular lesions and severity. Additional symptoms recorded included oral or regional pain, anorexia, malaise, lymphadenopathy, fever $\left(37.5^{\circ} \mathrm{C}\right.$, over 
$24 \mathrm{~h}$ ), headache, vomiting or other general symptoms.

Out of the above group of patients receiving TFX, an evident clinical improvement was observed in three cases with no recurrences during TFX treatment, in five the frequency, duration, extension and severity of recurrences were much lower than before immunotherapy with TFX, and in one case TFX administration did not change significantly the recurrence rate and the natural clinical course of facial herpes simplex (A. B. Skotnicki, unpublished observations).

As herpes labialis is generally constant in any one patient from recurrence to recurrence both in terms of triggering factors and the whole clinical entourage of HSV reactivation, the observed improvement during TFX immunotherapy suggests that thymic hormone could prevent or ameliorate the recurrent facial herpes simplex. Moreover, it was found that cessation of TFX administration was associated with the return of preimmunotherapy characteristics of the illness.

Of special interest are two female cases in whom facial or genital herpes simplex were triggered regularly for many years by menstruation. TFX, without changing the menstruation rate and duration, prevented HSV reactivation or significantly ameliorated clinical symptoms.

The above observations support the notion that TFX and probably other thymic factors could counteract - at least transiently during their application - the results of immunosuppressive events of different origin, which may be associated in predisposed individuals with the latent virus reactivation.

\section{PATIENTS WITH ACUTE HERPES ZOSTER}

Although herpes zoster is in the immunocompetent subjects a self-limiting condition, it causes severe pain during the acute phase, with subsequent post-herpetic neuralgia lasting often for many months. The reactivation of Varicella zoster virus occurs mainly in elderly persons showing a decline in cell-mediated immunity due to several triggering factors such as emotional upset, stress, fatigue, lymphoproliferative disorders or, in younger subjects, as the result of iatrogenic or viral immunosuppression (e.g. HIV infection).

Acute herpes zoster was considered a useful clinical model for studying the eventual indirect antiviral properties of thymic factors, as this disease in otherwise nonimmunocompromised subjects shows from patient to patient a similar natural course, in terms of sequential development of dermatological lesions, illness duration time and patient's complaints.

Thus, a placebo-controlled, double-blind study of TFX treatment for acute herpes zoster infection in primary nonimmunocompromised patients was conducted. Fifty-five consecutively hospitalized patients with zoster eruption of less than $96 \mathrm{~h}$ duration were considered for entry.

The patients were randomized for two groups, one (27 cases) receiving placebo $(10 \mathrm{mg}$ mannitol per vial) and the other (28 cases) receiving TFX for 3 weeks. The vials were coded and administrated as if all contained active drugs.

The clinical observations were noted daily and included: (1) time, number, size and dissemination of vesicles, (2) days until collapse of the last vesicle, (3) days until appearance of the first scab, (4) duration of pain, (5) dosage of analgesic required, (6) presence of fever. Simultaneously, photographic assessment was performed.

After breaking the code it was found that TFX administration resulted in the acceleration of cutaneous healing, reduction in the days of new lesion formation after day 0 , shorter duration of vesicles and shorter time to first and full crusting, as well as in amelioration of pain during the acute phase of the illness (A. B. Skotnicki et al., manuscript in preparation).

\section{PATIENTS WITH SEVERE LIFE-THREATENING STATES HOSPITALIZED IN THE INTENSIVE CARE UNIT}

The observed group consisted of 23 septic patients, aged 21-54 (mean $36 \mathrm{yr}$ ) with diffuse peritonitis and multiple body traumas ( 17 and 6 cases, respectively). They were admitted to the intensive care unit in hypovolemic shock and with respiratory insufficiency. The patients were subjected to typical life-supporting modalities, including blood, serum, fluid, albumin and $\gamma$-globulin infusions as well as antibiotics supplemented with TFX injections for 10-60 days (mean 23 days).

A constant monitoring of patients' respiratory and circulatory systems was performed, together with, every second day, checking of lymphocyte quantitative and qualitative parameters.

In 12 patients $(50 \%)$ the very severe clinical state improved until complete cure, with simultaneous increase of lymphocyte count from a mean of 815 $\mu l^{-1}$ to $2200 \mu l^{-1}$. They were suffering from acute pancreatitis associated with typical complications (three cases), multiple body traumas (four cases) and diffuse peritonitis due to gangrenous intestine with its wide resections (two cases). 


\section{Aleksander B. Skotnicki}

The remaining patients (11 cases) died with irreversible multiple organ failure. ${ }^{28}$ Similar results were obtained by Kiczka et al. in 20 subjects with sepsis and septic shock. ${ }^{29}$

The $50 \%$ cure in the group of patients with severe clinical state receiving TFX, when compared to the existing experience among such cases with no immunoenhancing treatment ( $60-70 \%$ mortality rate), seems to be encouraging. It is suggested that a systemic therapy approach, including thymic hormone administration, offers an increasing chance of saving life in immunocompromised-lymphopenic patients during sepsis, after multiple traumas and repeated anaesthesia and surgical operations.

\section{PATIENTS WITH ACUTE HEPATITIS}

In a placebo-controlled double blind trial in 60 patients with acute hepatitis $B, 15$ injections of TFX beginning from the day of diagnosis, resulted in significantly accelerated decrease of total bilirubin and iron levels, earlier clinical improvement and shorter necessary hospitalization period as compared to the control placebo group. There was no significant difference between the two groups in terms of other serological parameters. ${ }^{30}$

\section{PATIENTS WITH CHRONIC ACTIVE HEPATITIS B}

The value of immunotherapy with TFX in patients suffering from chronic active hepatitis $\mathrm{B}$ (CAH-B) has been tested in two clinical trials performed in Poland. In the Poznan study conducted in 30 patients with $\mathrm{CAH}-\mathrm{B}, \mathrm{HBsAg}+, \mathrm{HBeAg}+$, TFX was administered i.m. For 24 months (every day for the first 30 days, every second day for the 2nd month, and twice weekly thereafter) apart from transient pain and discomfort under the right costal arch, accompanied by flu-like syndromes which appeared during the first few weeks TFX injections, no other side effects were observed.

Biochemical studies revealed normalization of alanine transaminase levels in $60 \%$ of cases after 3 months of the treatment. There was no change in the HBsAg/anti-HBs system, but in $50 \%$ of cases seroconversion from $\mathrm{HBeAg}+$ into anti-HBe was observed (the rate of natural seroconversion in nontreated CAH-B patients was only $10 \%$ ).

During the course of TFX therapy the patients showed improvement in general condition, increased appetite, decreased liver size, a more rapid return to normal social, family and professional activities, as well as a disappearance of menstrual and male potency disturbances. In repeated liver biopsies, $66.6 \%$ of cases revealed an evolution of $\mathrm{CAH}$ into minimal or persistent hepatitis, $20 \%$ showed no change and $13.4 \%$ showed histological progression to liver cirrhosis. ${ }^{30-32}$

In the Warsaw study 21 patients (aged between 22 and $57 \mathrm{yr}$ ) were chosen for TFX therapy. The total duration of treatment to date has ranged from 12 to 36 months (mean $=18$ months).

It was found that TFX administration has a favorable effect on the clinical course of the disease, with subjective and objective improvement appearing after $10-15$ months of therapy. This effect was expressed by the disappearance of dyspepsia, diminished liver size and compactness, decreased splenomegaly in two cases, and resolution of ascites and edemas in one patient after the third year of TFX treatment. ${ }^{33}$

The normalization of serum values of transaminases, bilirubin, albumin, $\gamma$-globulin, cholinesterase, $\gamma$-glutamylotransferase, VII and $X$ clotting factors, and prothrombin time was observed in $60-80 \%$ of the cases. A marked drop in antinuclear and antismooth muscle antibodies was another finding. Seroconversion in HBsAg/anti-HBs system was observed in two patients. After 18 months of treatment seven patients remained $\mathrm{HBeAg}$-positive and in 14 patients the development of anti-HBe antibodies was found.

The histological pictures in the repeated liver biopsies (after 11-18 months of TFX therapy) showed a marked $(25 \%)$ or limited $(32 \%)$ resolution of mononuclear infiltration, no significant changes in $30.5 \%$ and progression into liver cirrhosis in $12.5 \%$ of cases. ${ }^{34}$

Taking into consideration that spontaneous improvement in liver function and histological picture occurs only in $20-30 \%$ of untreated patients with $\mathrm{CAH}-\mathrm{B}$, and that in $25-50 \%$ of cases the progressive liver tissue damage and cirrhotic replacement is observed, it seems that TFX may be a valuable therapeutic agent for the management of patients with CAH-B. Moreover, corticosteroids and other immunosuppressors do not offer better results and induce several severe side effects during the prolonged administration.

In an immunological monitoring system, TFX application resulted after between 3 and 6 weeks in a markedly increased percentage and number of $E$ rosetting cells. Subsequently (after 8-12 weeks), an increase of lymphocyte response in vitro to stimulation with ConA, followed by normalization of ConA-induced lymphocyte suppression was observed. Thereafter (between 16 to 20 weeks of 
treatment) a significant increase in reactivity to PHA was found. ${ }^{35}$

\section{PATIENTS WITH RHEUMATOID ARTHRITIS}

The pathogenesis of rheumatoid arthritis (RA) seems to be related to disturbed immunoregulation. The failure of cell-mediated immunity to eliminate the initiating pathogen and the insufficiency of suppressor $\mathrm{T}$-cells to regulate the immune response could explain B-cell hyperactivity and chronic inflammation in patients with RA.

The abnormality of the thymus-dependent immune function found both in murine and human autoimmune diseases and the ability of thymic extracts to normalize, at least in part, these disturbances support the notion that RA is, in fact, an immunodeficiency disease. As such, it could be treated causatively by substitution of thymus gland endocrine activity, i.e. by administration of thymus derived humoral factors, which could result in restoration of $\mathrm{T}$-cell immunoregulatory activity with subsequent suppression of hyperimmune phenomena.

To test the eventual role of TFX in management of RA patients a randomised prospective trial was performed in which 20 subjects received TFX for 3 months in daily s.c. injections. The control group of RA patients $(n=18)$ received as placebo normal saline administrated in the same way. Both groups received aspirin 'on demand'.

Out of the TFX group, 16 patients $(80 \%)$ showed a clinical improvement, manifested in both subjective (pain and morning stiffness) and objective (number of swollen and tender joints, muscle strength) parameters. Simultaneously, however, only in eight subjects $(40 \%)$ was a decrease in rheumatoid factor, $\alpha_{2}$ and $\gamma$-globulin levels with increase hemoglobulin and iron serum levels observed. A decreased requirement for aspirin administration was also noted. No compatible significant changes were found in the placebo group.

It must be stressed that in the majority of RA patients the clinical improvement was transient, lasting for a maximum of a few months of TFX immunotherapy. ${ }^{36}$

Similar results of TFX application in 20 patients with RA were observed by another author. ${ }^{37}$

Taking into consideration the lack of side effects, the immunonormalizing and bone marrowstimulating activities of TFX, as well as the recently found synergistic effect of TFX and aspirin on interleukin- 2 and interferon $\gamma$ production by activated T-cells, ${ }^{78,80}$ it was concluded that TFX may be of therapeutic value in the management of RA patients either alone or in combination with antiinflammatory or basic antirheumatoid drugs. ${ }^{8.80}$

\section{PATIENTS WITH MULTIPLE SCLEROSIS}

In the light of data suggesting a role of disturbed immunoregulation in the pathogenesis of multiple sclerosis (MS) a continuous combined immunomodulation therapy was proposed. ${ }^{38.39}$ The treatment schedule consisted of monthly cycles of nitrogen mustard (NM) in antiinflammatory, noncytotoxic doses $\left(0.01 \mathrm{mg} \mathrm{kg}^{-1}\right)$ administered i.v., for 5 consecutive days followed by levamisole (Lev) or TFX taken twice per week during the next 3 weeks. Each cycle was followed by the next one, irrespective of the disease activity, for at least $2 \mathrm{yr}$.

After the encouraging clinical results observed in 200 patients with MS subjected to this therapy schedule for 2-4 yr, a prospective randomized trial was performed. The study group consisted of 71 patients, including 37 patients with relapsing and 34 with chronic progressive course of the disease. Each group was further randomized into three subgroups of patients administered NM + Lev, NM + TFX or prednisone. The control group of MS patients received prednisone in decreasing doses (total 1225 $\mathrm{mg}$ ) during a 2 month course not more than twice per year.

The effect of therapy was evaluated every 3 months, based upon the neurological (numerical score) and disability status (Kurtzke scale) of the patients.

After 12-20 months of the trial, statistical analysis revealed a significant improvement of neurological state in MS patients with both types of the disease receiving NM + Lev as well as NM + TFX, but not in the control-prednisone group. ${ }^{41}$ These results of the ongoing trial suggest that the above therapeutic schedule consisting of alternating direct (NM) and indirect (Lev or TFX - through T suppressor cells) immune suppression in MS patients can influence the natural history of the disease by decreasing the annual relapse rate or by inhibition of further deterioration in MS subjects. In another group of MS patients receiving TFX for several months, the immunological assessment showed normalization of lymphocyte function and improvement in the clinical course of the disease. ${ }^{42}$

\section{PATIENTS WITH PSORIASIS}

Psoriasis is a relatively common chronic inflammatory papulosquamous skin disease with the loss or disturbances of normal epidermal cell differentia- 
tions in favor of proliferation (acanthosis and parakeratosis) with subsequent squamous exfoliation.

Moreover, the abnormalities in inflammatory and immune response are thought to play an important role in the pathogenesis and the course of the disease. The augmented monocyte activity (increased production and chemotaxis of monocytes, increased nitro blue tetrazolium dye reduction and the faster chemiluminescence response of monocytes with enhanced phagocytosis and killing by macrophages), together with an impairment of cellmediated immunity (decreased intradermal skin test reactions, T-cell lymphopenia, decreased blastogenesis and lymphokine production in response to mitogens and alloantigens) are found in most of the patients with psoriasis.

The T-cell defect might be produced by suppressor factors elaborated by activated monocytes. Alternatively, this impairment might represent an attempt by the organism to down-regulate the inflammatory response as compensation for the overactive monocytic population.

Among the aggravating factors leading to the disease - which should be looked for and prevented, or their effects corrected - the severe anxiety, fatigue states, skin irritation and severe sunburn and viral or bacterial infections are taken into main consideration. In particular, throat and upper respiratory streptococcal infections may flare into guttate psoriasis both in children and adolescents.

As contemporary treatment modalities allow only for transient amelioration of symptoms without effect on the disease recurrences, the immunomodulation trial using TFX was performed.

The group of 72 patients with various types of the disease ( 30 cases with guttate-rash psoriasis, 17 with exfoliative psoriasis, 16 with stationary psoriasis and 9 cases with psoriatic arthritis) and different extension of psoriatic lesions (4 cases with less than $10 \%$ skin involvement, 27 with less than $50 \%$, and 41 with widespread lesions). Altogether, of 72 observed patients, $33(46 \%)$ presented with severe course of the diseases with several hospitalizations and relative resistance to conventional forms of therapy.

TFX was administrated intramuscularly three times per week for the first month and twice weekly thereafter for 1-2 yr.

The immunotherapy with TFX resulted in clinical improvement, with retirement of psoriatic lesions in 55 patients $(76.4 \%)$. The effect was considered as very good in 23 cases and in 32 as encouraging. In 17 cases $(23.6 \%)$ no effect of TFX on the clinical course of the disease was observed.

Clinical improvements were also found among patients considered as presenting the severe form of the disease: an excellent response was observed in 11 cases $(33 \%)$ and a good one in 12 patients $(36 \%)$, in 17 cases, no response.

The retreat of psoriatic lesions took place in the majority of responders after the first 2 weeks of TFX injection. In ten cases the clinical improvement was followed by long-lasting disease remission (24 months) despite the previous two to three recurrences per year. In another 13 cases the flares of psoriasis were of decreased severity and responded to short period topical treatment. A decreased sensitivity to viral and bacterial infections and improvement of general clinical state and well-being was also observed during TFX application. ${ }^{43.44}$

\section{PATIENTS WITH SCLERODERMA}

During 4 yr (1983-86) 27 patients with scleroderma were evaluated for the effect of TFX on clinical and laboratory parameters. This group consisted of 22 female and 5 male subjects between 12 and $63 \mathrm{yr}$ old with the disease lasting from 3 months to 30 years. The disease characteristics allow for the group to be subdivided into 18 patients with acrosclerosis, five with progressive systemic sclerosis and four patients with multifocal circumscribed scleroderma (morphea). The patients showed typical symptoms and findings for scleroderma.

TFX was administrated for $30-60$ days by intramuscular injections (10-20 mg) every 10 months for 3-4 yr. The thymotherapy resulted in marked subjective and objective improvement in 16 patients $(59 \%)$ and in mediocrine amelioration in nine cases $(33 \%)$. The clinical improvement was manifested by decreased Raynaud's phenomenon, a decrease in stiffness and tightness of the fingers' skin, healing of the chronic painful ulcerations of the ends of the digits, reappearance of fairly normal skin folds and wrinkles (e.g. the face less masklike), a diminishing of skin tension and disappearance of multiple sclerotic changes on trunk and limbs, diminishment or disappearance of polyarthralgia, increased temperature of distal parts of the body $\left(1.5^{\circ}-2^{\circ} \mathrm{C}\right)$, amelioration of esophageal motility disturbances with improvement of peristaltic activity (resulted in diminishing of dysphagia and substernal burning or fullness after meals) and disappearance or decreased abdominal pain with episodic diarrhoea and constipation.

In some of the patients, amelioration of cardiorespiratory symptoms, mainly diminished dyspnoea on exertion, despite persistence of spirometric, radiological and electrocardiological abnormalities was noted. 
Accelerations in growth and weight gain were observed in three pediatric cases. In some of the cases the clinical improvement was long-lasting, in others it disappeared after cessation of the TFX treatment.

In 21 cases from the above group (78\%) severe $\mathrm{T}$-cell lymphopenia was found. The number of $\mathrm{T}$ lymphocytes increased after 1-3 months of TFX application together with a drop in $\gamma$-globulin levels, which correlated in some of the cases with clinical improvement.

The authors concluded that thymotherapy with TFX in patients with scleroderma resulted in amelioration of symptoms and signs and in, at least transient, inhibition of the disease progression. ${ }^{45}$

\section{PATIENTS WITH DERMATOMYOSITIS}

Dermatomyositis is an inflammatory disease of skeletal muscles with symmetrical weakness of the limb girdles and pharynx, together with typical skin rash. The leading theory of the pathogenesis of dermatomyositis attributes muscle damage to cellmediated autoimmunity. Evidence that supports this hypothesis includes the presence of lymphocytes and macrophages in the inflammatory infiltrate, the sensitivity of lymphocytes to muscle antigens in vitro, and the direct cytotoxicity of lymphocytes to cultured muscle cells. The presence of intramuscular vascular deposits of immunoglobulin and $\mathrm{C}_{3}$ have been also demonstrated. The hyper- and abnormal sensitivity has also been implicated by the frequent relation to previous infection, association with symptoms common to other connective tissue diseases and the disease appearance secondary to malignancy.

The preliminary immunomodulation trials with TFX were performed by four different groups in four cases of dermatomyositis. ${ }^{46-49}$ The group of patients consisted of one male and two female subjects, aged 19, 22, 24 and $31 \mathrm{yr}$, with typical symptoms and signs of dermatomyositis, including one tetraplegic bedridden case due to muscle weakness and wasting.

They all showed relative resistance to steroids and cyclophosphamide and/or presented iatrogenic haemorrhagic gastritis and Cushing's syndrome. After discontinuation of immunosuppressive therapy, TFX was administered i.m. at a dose of $10 \mathrm{mg}$ per day for several months. In all cases, immunotherapy with TFX resulted in a gradual decrease in muscular weakness, discomfort or tenderness in the proximal muscles, normalization of depressed reflexes, amelioration of arthralgia, and movement restriction in the hip and shoulder girdles, with reappearance of the ability to rise from a chair or bed and raises the arms above the head, as well as to climb the stairs. The observed dysphagia in two cases, secondary to weakness of pharyngeal muscles and hypotonicity of the upper part of the esophagus, disappeared after 4 weeks of TFX therapy. A retirement of edema and typical heliotrope rash on the upper eyelids as well as erythema on the forehead was also observed in two cases. ${ }^{46-49}$

Clinical improvement was associated with the normalization of the high serum levels of musclederived enzymes, principally creatine phosphokinase, transaminase (SGOT, SGPT), lactate dehydrogenase (LDH) and aldolase. (The levels of these enzymes correlate reasonably well with the disease activity and are commonly used in monitoring therapy effectiveness in patients with dermatomyositis.)

Simultaneous qualitative and quantitative recovery of the T-cell compartment of the immune system (the rise in peripheral blood T-cell numbers, increased in vitro reactivity to Con A - with generation of T-suppressor cells - and subsequently to PHA after several months of TFX administration) ${ }^{46}$ support the notion that:

(1) dermatomyositis is pathogenetically related, at least in part, to the acquired deficit of homeostatic function of T-cells, and

(2) that clinical improvement during TFX administration resulted from efficient immunoreconstructive effect of this thymus extract in the observed patients.

TFX was used also in patients with other chronic skin diseases resistant to conventional treatment, e.g. with contact eczema, blastomycosis, recurrent furunculosis, atypical purulent lesions, alopecia atrophicans and prurigo. In several of the above cases a complete or almost complete retreat of the topical lesions have been obtained. The underlying immune deficiency found in all subjects were corrected simultaneously with clinical improvement. $^{48-50}$

\section{PATIENTS WITH RECURRENT APHTHOUS STOMATITIS (RAS)}

An open trial was performed in five patients who had suffered from RAS for 2-8 yr. The pathogenesis of the disease - characterized by periodic, recurrent, oral ulcerations - seems to be related to various abnormalities of immune reactivity with local immune complex formation. As no drug is known to be effective in preventing recurrences of 
RAS, immunoregulatory treatment with TFX was initiated. TFX was applied two times weekly for 1-2 yr. This trial showed an overall beneficial effect of TFX in four out of five patients, expressed by decreased frequency and severity of attacks with the reduction of duration and pain of the ulcerative lesions in two patients, and the complete disappearance of diseases episodes in two others. In the latter patients, however, the discontinuation of TFX administration was followed after 7 and 12 months, by the return of the pretreatment picture of the disease. $^{8}$

\section{PATIENTS WITH CHRONIC LYMPHOCYTIC LEUKEMIA (CLL)}

In 14 out of 20 untreated patients with early CLL, TFX caused a decrease of total lymphocyte count with a simultaneous increase of E-rosette forming cells, lymphocytes with high lysosomal acid phosphates activity, immunoglobulin levels, increase in reticulocyte counts and hemoglobulin levels, and normalization of tuberculin skin sensitivity in previously energic subjects. ${ }^{51,52}$

\section{PATIENTS WITH HODGKIN'S DISEASE (HD)}

In ten patients with advanced disease (stages III and IV), TFX administration resulted in an increased lymphocyte count (even in patients with histological picture of lymphocyte depletion), increased T-cell-mediated - immunity (skin tests, E-rosettes, PHA response) and improvement of hematological tolerance in patients simultaneously receiving cytostatic drugs or radiotherapy. The administration of TFX in HD patients with simultaneous mycobacterial or viral infections was found to be of important supportive therapeutic value. ${ }^{53}$ The advanced Hodgkin's disease, as a syndrome of 'hypolymphocytic hypothymism' seems to be, one of the most suitable and promising pathological situations as candidate for thymotherapy, performed together with or after conventional treatment. ${ }^{8}$

\section{PATIENTS WITH PRIMARY LUNG CANCER}

The randomized prospective open trial included 135 patients with primary lung cancer. Histologically, the above population contained 96 cases with undifferentiated cell carcinoma, 37 with squamous cell carcinoma, and two cases with adenocarcinoma. Out of the total population, 53 patients were chosen randomly for the TFX study and the remaining 82 served as control.

Twelve patients from the TFX group out of 40 patients with advanced bronchogenic cancer were excluded from conventional treatment because of the disseminated disease process, or the coexisting disease, 28 received only symptomatic treatment (control group), which was supplemented in the remaining 12 cases (studied group) with TFX (administered twice weekly for 10 weeks). TFX injections resulted in subjective and objective clinical improvement in ten out of twelve patients, correlated with the inhibition of local growth and metastatic spreading to mediastinal lymph nodes or other organs. In three patients, partial regression of tumor mass was observed. The 6 month survival time in this group was $42 \%$, comparing to $7 \%$ in the control group.

The patients with less advanced bronchogenic carcinoma $(n=95)$ were admitted to cobalt therapy $\left({ }^{61} \mathrm{Co}\right)$. They were randomized for two groups: the control one receiving ${ }^{60} \mathrm{Co}$ alone $(n=54)$ and the combined therapy group $(n=41)$ in which irradiation was associated with 5 months TFX administration. It was found that TFX favorably influenced the 6 and 12 months survival time (69 and $38 \%)$ as compared to the control group subjected to radiotherapy alone (31 and 7\%, respectively).

Interestingly, the patients who received TFX (total dose $300 \mathrm{mg}$ ) during radiotherapy showed enhancement of delayed hypersensitivity reaction (DHR), to PPD in $39 \%$, as compared to $12 \%$ in the control group. This reinforcement of cell-mediated immunity was correlated with the mean survival time, which increased from 13.2 months to 18.4 months in ${ }^{60} \mathrm{Co} / \mathrm{TFX}$ groups in patients who showed improvement in DHR. Similar data for the control ${ }^{60}$ Co group were 7.2 months and 8.8 months, respectively. An evident improvement of hematological tolerance to irradiation (less anaemic and leucopenic subjects) was observed in the ${ }^{60} \mathrm{Co} / \mathrm{TRX}$ group. $20,54,55$

\section{PATIENTS WITH COLORECTAL CANCER}

In 50 patients with inoperable diseases, the longlasting repeated TFX injections caused an increase in granulocyte and lymphocyte counts with enhancement of cell-mediated immunity, clinical improvement and increased survival time. In 12 cases subjected to TFX immunotherapy the repeated evaluation of histological changes within the tumor tissue has been completed. These changes included inflammatory, granulomatous and fibroblastic reac- 
tions with focal calcification and tumor necrosis. Similar microscopic changes within the stroma tissue at the margin of the neoplastic growth are seen in cases of spontaneous tumor regression and are considered as the expression of the natural host response to the invasion of neoplastic tissue. Thus, it is possible that the evident prolongation of survival time of the observed patients was due to the mobilization by TFX of local tissue defense reactions against tumor growth. ${ }^{56-58}$

In recently presented data summarizing $15 \mathrm{yr}$ experience in 457 patients with malignancies of the gastro-intestinal tract and breast cancer, the same authors suggest that application of TFX before and after various surgical (especially repeated) procedures was associated with diminished incidence of postoperation complications, with better, accelerated wound healing and increased survival time as compared to comparable subjects who received no immunotherapy. ${ }^{59}$

The regression of metastatic gastric cancer (confirmed by autopsy) was described in a patient receiving long term TFX immunotherapy. ${ }^{60}$

The above clinical observations confirmed the experimental studies showing the inhibitory effect of TFX on transplantable tumor growth in mice. ${ }^{61}$

\section{PATIENTS WITH CHRONIC KIDNEY GRAFT REJECTION}

An immunomodulatory trial with TFX was initiated in 40 patients with histologically and biochemically proved chronic kidney graft rejection and relative resistance to chemical immunosuppression. This immunotherapy resulted in improvement of kidney function (decreased serum creatinine level) in $40 \%$ of cases, in other in an evident slowing down of the progressive rejection process. It was concluded that the antibody-mediated chronic kidney graft rejection could be effectively inhibited or delayed with thymic hormones. ${ }^{62-64}$

\section{CONCLUDING REMARKS}

The 15 yr clinical experience with TFX gained independently by several Polish medical centers and presented here, suggests that this calf thymusderived factor has therapeutic value in many ostensibly nonrelated human diseases (Table 1). Superficial sceptics, deprived of wide clinical experience and underestimating the homeostatic power of immune system, could say that TFX (and other thymic factors) acts as a panacea, and thus - as a remedy for different diseases - has no biological activity. In pharmacology 'panacea' has traditional peiorative meanings, but the above described clinical disorders responded to or ameliorated by TFX despite such different clinical appearances, being subject to the interest of several branches of medicine, having different prognosis, and being in the past treated with different therapeutic modalities have some common characteristics. They are in the majority chronic, remitting-relapsing, selfperpetuating or progressive diseases associated with qualitative or quantitative disturbances of $\mathrm{T}$-cellmediated compartment of immune system. ${ }^{8.65}$

The pathogenesis of the secondary T-cell immunodeficiencies found in smaller or greater degree in the above diseases seems to be related to genetic predisposition, ecological immunotoxicant exposure, hormonal disturbances and recurrent infections with inability of the organism to eradicate the invading pathogen. ${ }^{39}$ The group of disorders taking advantage of defective thymus-dependent immunity in terms of their development, clinical course and complications included increased sensitivity to recurrent infections, autoimmune diseases of different type and target organ or tissues injury, and some malignant (especially lymphoproliferative) syndromes.

In the treatment of such disorders 'the pro-host approach' intended to restore a faltering immune system or to reequilibrate an immune dysfunction cannot be ruled out if the optimal therapeutic result is going to be achieved. The concept of treating a defective immune system is compatible to therapy of circulatory, respiratory, liver, kidney or bone marrow failure or insufficiency. ${ }^{8}$

The above approach can be realized by substitution of endocrine thymic function by thymic humoral factors or thymomimetic drugs. The observed sequence of immunorestoration induced by longlasting (several months) TFX administration being similar to the ontogenic development of lymphocyte immunocompetence - suggests the physiological effect of this thymic factor on target cell population. ${ }^{65}$ Immunotherapy with TFX is reasonable not only as a supportive measure for immunosuppressed or infected patients but also as a preventive approach in subjects with past history of recurrent infections or disease exacerbations, to counteract the immunosuppressive or immunodisturbing effects of known triggering factors. ${ }^{77}$

Our clinical experience with TFX to date has shown that this preparation causes an increase in general and local immune responses, expressed by more rapid elimination of infectious agents (viral, bacterial, mycotic) and by clearing of organ pathology (e.g. improved liver function in cases of chronic hepatitis, or functional amelioration of peripheral 
Table 1. Clinical trials with TFX-POLFA (1973-1988)

\begin{tabular}{|c|c|c|}
\hline Diagnosis & No. of patients & References \\
\hline Primary immunodeficiency states & 7 & 18,73 \\
\hline \multicolumn{3}{|l|}{ Infections: } \\
\hline in adults & 188 & $21,22,74$ \\
\hline in children & 10 & 27 \\
\hline recurrent herpes labialis & 8 & Unpubl. \\
\hline acute herpes zoster & 28 & Unpubl. \\
\hline sepsis & 38 & 28,29 \\
\hline recurrent aphthous stomatitis & 5 & 8 \\
\hline HIV infection & 20 & 81 \\
\hline acute viral hepatitis $B$ & 30 & 30 \\
\hline \multicolumn{3}{|l|}{ Autoimmune disorders } \\
\hline chronic active hepatitis $B$ & 61 & $32,34,66,67$ \\
\hline rheumatoid arthritis & 40 & 36,37 \\
\hline multiple sclerosis & 38 & $40,41,42$ \\
\hline \multicolumn{3}{|l|}{ Dermatological diseases } \\
\hline psoriasis & 72 & 43,44 \\
\hline scleroderma & 27 & 45 \\
\hline dermatomyositis & 4 & $46-48$ \\
\hline Primary or secondary leucopenia & 123 & $8,18-20$ \\
\hline \multicolumn{3}{|l|}{ Oncological conditions } \\
\hline Hodgkin's lymphoma & 10 & 53 \\
\hline chronic lymphocytic leukaemia & 20 & 51,52 \\
\hline primary lung cancer & 53 & $20,54,55$ \\
\hline colorectal cancer & 250 & $56-58$ \\
\hline Total & 1032 & \\
\hline
\end{tabular}

nervous system in cases with polyneuropathies. $^{8,18,32,34,66,67}$

Secondly, TFX suppresses autoimmune phenomena with improvement of target organ function (e.g. decreased symptoms and signs in patients with rheumatoid arthritis). ${ }^{36,37,39,68}$

Thirdly, TFX counteracts the myelo- and immunosuppressive properties of cytostatic agents by a stimulating influence on haemo- and lymphopoietic restoration after iatrogenic damage. $19,20,69-72$

Finally, it regulates the humoral immune response, by increasing Ig levels in patients with primary or secondary hypo- $\gamma$-globulinemia and by inhibiting $\mathrm{Ig}$ production in cases of hyper- $\gamma$ globulinemia. $^{8,39,73,76}$

Thus, substitution of thymus function could create an effective obstacle against the development of symptomatically different, but pathogenetically similar human diseases. The beneficial effects of TFX immunotherapy observed in a broad spectrum of human pathology depend, most likely, upon the correction by TFX of the common pathogenetic T-cell-mediated immune abnormalities. ${ }^{8,35.77-79}$ Taking into consideration the lack of side effects of this organ preparation, its relatively low price and facility even in self application, TFX can be used in both immune prophylaxis, as well as in immune intervention. ${ }^{1,2,18}$ As in every substitution therapy, TFX should be used constantly in repeated therapeutic cycles, especially in patients with immunodeficient-related or chronic immune-mediated diseases. ${ }^{39,80}$

\section{REFERENCES}

1. Aleksandrowicz J, Turowski G, Czarnecki J, Szmigiel Z, Cybulski L, Skotnicki A B: Thymic factor X (TFX) as a biologically active extract. Ann Immun 7, 97 (1975).

2. Czarnecki J, Jaskolski B: Preparation TFX-Polfa Jelenia Gora. Arch Immun Ther Exp 26, 475 (1978).

3. Skotnicki A B: The biological activity and physicochemical properties of the thymus extract TFX. Pol Tyg Lek 33, 1119 (1978).

4. Staroscik K, Boratynski J, Lisowski J: Properties of TFX, a product obtained from calf thymus. Arch Immun Ther Exp 26, 477 (1978).

5. Slopek S, Gieldanowski J, Kowalczyk-Bronisz S H: Immunobiological and pharmacological properties of thymus factor X (TFX). I. Biological and pharmacological activity. Arch Immun Ther Exp 28, 827 (1980).

6. Gieldanowski J, Kowalczyk-Bronisz S H: Investigations on immunological and pharmacological activities of thymus factor X (TFX). Arch Immun Ther Exp 26, 483 (1978).

7. Gieldānowski J, Slopek S, Kowalczyk-Bronisz H: 
Immunological and pharmacological properties of thymus factor $X$ (TFX). II. Immunotropic activity. Arch Immun Ther Exp 28, 853 (1980).

8. Skotnicki A B, Dabrowska-Bernstein B K, Dabrowski M P, Gorski A, Czarnecki J, Aleksandrowicz J: Biological properties and clinical use of calf thymus extract TFX-Polfa, in Goldstein A L (ed): Thymic Hormones and Lymphokines, pp. 545-564, New York, Plenum Press (1984).

9. Goodman J W, Basford N L, Shinpock S G: On the role of thymus in hemopoietic differentiation. Blood Cells 4, 53 (1978).

10. Zipori D, Trainin N: The role of thymic humoral factor in the proliferation of bone marrow CFU-S from thymectomized mice. Exp Hemat 3, 389 (1975).

11. Jaszcz W, Chlap Z, Turowski G, Piotrowska K: Studies on biologic activity of thymic extract (TFX). I. Effect on the blood picture and lymphatic organs in mice. Patol Pol 26, 387 (1975).

12. Wazewska-Czyzewska M, Aleksandrowicz J, Szybinski Z, Kulig D, Plonka I, Skotnicki A B: The effect of calf thymus extract TFX, on the survival of mice exposed on ionizing radiation. Pol Przegl Rad Med nukl 41, 51 (1977).

13. Jaszcz W, Rzepecki W, Wojceiwski Z, Piotrowska K: The effect of TFX on the pictures of the blood and lymphatic organs of thymectomized mice in the postneonatal period. Patol Pol 31, 273 (1980).

14. Skotnicki A B, Gorski A, Gaciong Z, Korczak G: The effect of thymus extract on in vitro proliferation of hematopoietic progenitor cells. Fedn Proc Fedn Ann Soc exp Biol 39, 4696 (1980).

15. Gorski A, Skornicki A B, Gaciong Z, Korczak G: The effect of calf thymus extract TFX on mouse and human hemopoiesis. Thymus 3, 129 (1981).

16. Raberger $G$, Gieldanowski $J$ : The influence of thymus factor $\mathrm{X}$ (TFX) and its fraction $\mathrm{V}$ on the haemodynamic and haemopoietic functions. Arch Immun Ther Exp 33, 319 (1985).

17. Miszta H, Dabrowski Z, Zdunczyk A, Skotnicki A B, Piastucka B: Biological response modifiers influence the PHA-induced production of CSF by human peripheral blood lymphocytes, in Symposium Haematologicum, Zakopane, Nov. 6-7, Abstracts, p. 45 (1984).

18. Aleksandrowicz J, Blicharski J, Janicki K, Lisiewicz J, Skotnicki A B, Sliwczynska B, Turowski G, Szmigiel Z, Wazewska-Czyzewska M: Effect of the thymus extract on congenital hypogammaglobulinaemia and immunological deficiency accompanying the proliferative and aplastic haematological diseases, in van Bekkum D K (ed): Biological Activity of Thymus Hormones, pp. 37-39. Rotterdam, Kooyker (1975).

19. Skotnicki A B, Blicharski J, Lisiewicz J, Sasiadek U, Janik J, Wolska T, Zdunczyk A, Aleksandrowicz J: Calf thymus extract TFX-Polfa in the treatment of patients with secondary leukopenia. Ther Drugs 37, 95 (1987).

20. Zeromski J, Slowik-Gabryelska A, Krzysko R: The preliminary evaluation of TFX administration in advanced bronchogenic carcinoma, in Seminar on Cellular and Humoral Immunity in Lung Diseases, pp. 44-46. Poznan (1976).
21. Stankiewicz-Szymczak W, Moszynski B, Dabrowski M P, Dabrowska-Bernsztein B K, Stasiak A: The initial results of TFX-Polfa application in patients with chronic recurrent infections of upper respiratory tract. Pol J Otolaryng 2, 350 (1986).

22. Matusiewicz $R$, Wasniewski J, Kowalczyk $M$, Lebiedowski K, Czajkowski M: The effect of TFXPolfa on peripheral blood granulocyte migration and phagocytize ability in patients receiving long term steroid therapy, in Chyrek-Borowska S (ed): Immunomodulation (Bialowieza), p. 47. Polish Immunological Society (1987).

23. Gieldanowski J: Immunomodulators - Thymus Factor $\mathrm{X}$ (TFX) and levamisole in immune reactions and inflammatory processes. Arch Immun Ther Exp 29, 121 (1981).

24. Kiczka W, Lawniczak C, Szkaradkiewicz A, Czarnecki J, Pesic M: Thymic extracts stimulate phagocytosis of granulocytes and macrophages. Immun Pol 8, 247 (1983).

25. Wysocki H, Kiczka W, Wierusz-Wysocka B, Szczepanik A, Czarnecki J: The influence of thymus extract (TFX) on the phagocytic and the bactericidal capacity of polymorphonuclear neutrophils from patients with insulin-dependent diabetes mellitus. Thymus 7, 271 (1985).

26. Smogorzewska E M, Korczynska M, Golebiowska J: The effect of calf thymus extract (TFX) on human T lymphocyte and neutrophil mobility and chemotactic response in vitro. Thymus 4, 257 (1985).

27. Radomska G, Jankowski A, Prusek W: Immunomodulation in children with recurrent infections of respiratory tract, in Chyrek-Borowska $S$ (ed): $1 \mathrm{~m}$ munomodulation (Bialowieza), p. 46, Polish Immunological Society (1987).

28. Trybus-Galuszka $H$, Osenko $G$, Gedliczka $O$, Turowski G: Immunomodulation in patients with severe life-threatening states hospitalized in intensive care unit, in Chyrek-Borowska S (ed): Immunomodulation (Bialowieza), p. 41. Polish Immunological Society (1987).

29. Kiczka W, Szulc R, Jurczyk W, Lawniczak Cz, Gaca M: TFX Polfa in the treatment of patients with sepsis or septic shock, in: 4th World Congress on Intensive and Critical Care Medicine, Jerusalem, Abstract 45. (1985).

30. Kiczka W, Juszczyk J, Adamek J, Ozynski R: Thymic factor $X$ (TFX) in the treatment of acute and chronic active hepatitis type B, in: $I X$ International Congress of Infections and Parasitic Diseases (Munich) (1986).

31. Juszczyk J: Preliminary evaluation of the therapeutic results in patients with chronic active hepatitis (HBsAg+) receiving calf thymus extract (TFXPolfa). Pol Tyg Lek 39, 1085 (1984).

32. Kiczka W, Juszczyk J, Adamek J: The therapeutic results of TFX in patients with chronic active hepatitis. Pol Tyg Lek 42, 192 (1987).

33. Dabrowska-Bernstein B K, Dabrowski M P, Cianciara J, Brzosko W J, Babiuch L, Kassur B: The treatment of chronic aggressive hepatitis with Polish Thymus Factor (TFX). Erfahrungsheilkunde 29, 71 (1980).

34. Cianciara J, Babiuch L, Gorska E, Kassur B: Immunotherapy of patients with chronic active hepa- 
titis (HBsAg+) with TFX. Clinical opinion. Pol Tyg Lek 39, 1097 (1984).

35. Dabrowski M P, Dabrowska-Bernstein B K, Brzosko W J, Babiuch L, Kassur B: Immunotherapy of patients with chronic virus $B$ hepatitis. I. Maturation of human T-lymphocytes under influence of calf thymic hormone. Clin Immun Immunopath 16, 297 (1980).

36. Skotnicki A B, Hoszowska B, Szerla J, Biedowa E: The effect of calf thymus extract TFX-Polfa on clinical and laboratory parameters in patients with rheumatoid arthritis, in: Abstracts, 6th International Congress Immunology, p. 679. Toronto (1986).

37. Rutowicz L: TFX in the treatment of patients with rheumatoid arthritis, in Chyrek-Borowska S (ed): Immunomodulation (Bialowieza), p. 38. Polish Immunological Society (1987).

38. Aleksandrowicz J, Blicharski J, Retinger M, Skotnicki A B, Zdunczyk Z: Some aspects of immunopathogenesis of multiple sclerosis and therapeutic perspectives. Pol Tyg Lek 13, 1363 (1981).

39. Skotnicki A B: Immunoregulatory treatment in autoimmunoaggressive syndromes. Post Hig Med Dosw 37, 345 (1983).

40. Skotnicki A B, Aleksandrowicz J, RetingerGrzesiula M, Zdunczyk A, Grochmal S, Huczynski J: Multiple sclerosis: immune pathogenesis, up to date therapeutic strategy and the combined immunoregulatory treatment. Post Hig Med Dosw 37, 345 (1983).

41. Hertmanowska $H$, Zielinska M, Kutzner K, Skotnicki A B: The combined immunomodulatory treatment in patients with multiple sclerosis, in: Abstracts. Second International Workshop on Neuroimmunomodulation, p. 126. Dubrovnik (1986).

42. Dabrowski M P, Dabrowska-Bernstein B K, Stasiak A, Gajkowski K, Korniluk S: Immunologic and clinical evaluation of multiple sclerosis patients treated with corticosteroids and/or calf thymic hormones. Ann N Y Acad Sci 496, 697 (1987).

43. Turowski G, Sanokowska E, Dynowska D, KapinskaMrowka M, Chomiak-Stachura E: Influence of TFX on immunological response and clinical course of patients with psoriasis. Prog Dermat, Poznan 4, 209 (1987).

44. Kapinska-Mrowka M, Turowicz G: Clinical observations of patients with psoriasis treated with TFX, in Chyrek-Borowska S (ed): Immunomodulation (Bialowieza), p. 49. Polish Immunological Society (1987).

45. Stepien B, Bowszyc J, Janicka D, Zaba R: TFX-Polfa in the treatment of patients with scleroderma. Prog Dermat, Poznan 4, 225 (1987).

46. Stasiak A: Successful immunotherapy with TFX-Polfa in a patient with acute dermatomyositis. Pol Tyg Lek 13, 389 (1983).

47. Zdunczyk A, Aleksandrowicz J, Skotnicki A B: An attempt to treat dermatomyositis with TFX-Polfa. Pol Tyg Lek 40, 1103 (1985).

48. Turowski G, Dynowska D, Sanokowska E: Influence of thymic extract (TFX-Polfa) on selected skin diseases. Prog Dermat, Poznan, 4, 199 (1987).

49. Stepien B, Janicka D, Bowszyc J, Zaba R: Dermatomyositis treated with Polish thymic preparation TFX. Prog Dermat, Poznan 4, 233 (1987).
50. Dynowska D, Sanokowska E, Turowski G: The effect of thymus extract (TFX) on atopic dermatitis. Immun Pol 8, 226 (1983).

51. Wazewska-Czyzewska $M$, Aleksandrowicz J, Turowski G, Blichski J, Dobrowolski J, Dolezalowa M: A trial of immunological stimulation with thymic extract (TFX) in untreated chronic lymphocytic leukemia. Acta Med Pol 17, 97 (1976).

52. Skotnicki A B, Thomson A E R, Tisdale M J: The influence of calf thymus extract on lymphocyte populations in chronic lymphocytic leukemia, in Rainer H (ed): Immunotherapy of Malignant Diseases, pp. 27-30. Stuttgart, New York, Schattauer (1978).

53. Marjanska-Radziszewska J, Bicz-Ciecialowa $\mathbf{M}$, Szmigiel Z, Skotnicki A B: Application of the thymic extract in patient suffering from Hodgkin's disease, in: XI Congress of the Polish Haematological Society, Abstracts, p. 118. Gdansk (1975).

54. Slowik-Gabryelska A, Krzysko R: The relationship between the dose of TFX and the clinical course of primary lung cancer. Pneum Pol 48, 187 (1980).

55. Krzysko R, Slowik-Gabryelska A: TFX in primary bronchial cancer and some indices of its activity. Immun Pol 7, 152 (1981).

56. Turowski G, Cybulski L, Politowski M, Turaszwili T, Zubel M: First trials of immunopotentiation by thymic extract (TFX) in surgical patients with malignant disease. Acta med pol 17, 18 (1976).

57. Urban A, Turowski G, Cybulski L: The histological changes of the colon and rectum cancers stroma observed in patients after immunopotentiation by thymus extract (TFX). Patol Pol 28, 47 (1977).

58. Cybulski L, Turowski G, Politowski M, Urban A, Turaszwili $T$, Zubek M: Initial observations on the application of thymus extract (TFX) in patients with alimentary tract neoplasm. Pol med Sci Hist Bull 15, 47 (1976).

59. Cybulski L, Turowski G: The effect of TFX on surgical therapy. Clinical consideration based on 14 years observations, in Chyrek-Borowska $S$ (ed): Immunomodulation (Bialowieza), p. 42. Polish Immunological Society (1987).

60. Hryniewiecki J, Kiczka W: Regression of gastric cancer with metastases following immunostimulation treatment confirmed by autopsy. Int $J$ Immunother 1 , 47 (1985).

61. Chlap Z, Jaszcz W, Turowski G: The influence of calf thymus extract (TFX) on growth of the subcutaneous transplant of Ehrlich's carcinoma. Mat med pol 17, 37 (1984).

62. Gorski A, Korczak-Kowalska G, Nowaczyk M, Gaciong Z, Skopinska-Rozewska E: Thymosin, an immunomodulator of antibody production in man. Immunology 47, 497 (1982).

63. Gorski A, Paczwk L, Rancewicz A, MokrzyckaMichalik M, Korczak-Kowalska G, Dierzanowska D: Factors affecting immunoglobulin production of lymphocytes from renal allograft recipients. Transplantn Proc 15, 825 (1983).

64. Gorski A, Orlowski T, Korczak-Kowalska G, Nowaczyk M, Wasik M, Podobinska I: Suppression of immune functions in vivo with cyclophosphamide: enhancement of suppression by thymosin (TFX). Transplantn Proc 17, 1339 (1985). 
65. Dabrowski M P, Dabrowska-Bernstein B K (eds): Immunoregulatory Role of Thymus. Boca Raton, FL, CRC Press, in press.

66. Dabrowska-Bernstein B K, Dabrowski M P, Stasiak A, Wasowska B, Brzosko W J: Immunotherapy of the chronic active viral hepatitis $(\mathrm{HBsAg}+)$ with calf thymus extract (TFX-Polfa). Pol Tyg Lek 39, 1089 (1984).

67. Dworniak D, Baj Z, Pokoca L, Majewska E, Dribnik $S$, Tchórzewski H, Zeman K: The use of TFX in the treatment of patients with chronic active hepatitis B, in Chyrek-Borowska S (ed): Immunomodulation (Bialowieza), p. 40. Polish Immunological Society (1987).

68. Fiedorowicz-Fabrycy I, Sochacka-Kuzko B, Ostanek L, Glab-Kordecka E, Urasinski I: The effect of immunomodulatory treatment in patients with connective tissue diseases, in Chyrek-Borowska $S$ (ed): Immunomodulation (Bialowieza), p. 39. Polish Immunological Society (1987).

69. Aleksandrowicz J, Skotnicki A B: The role of the thymus and thymic humoral factors in immunotherapy of aplastic and proliferative diseases of the haemopoietic system. Acta med pol 17, 1 (1976).

70. Aleksandrowicz J, Blicharski J, Cichocki T, Dobrowolski J, Kwiatkowski A, Lisiewicz J, Sasiadek U, Skotnicki A B, Warzewska-Czyzewska M: The effect of calf thymus extract on surface structure and lysosomal apparatus in lymphocytes of patients with chronic lymphocytic leukemia. Haematologica 63, 267 (1977).

71. Skotnicki A B: Thymus extract - TFX - in the treatment of bone marrow hypoplasia. Erfahrungsheilkund 29, 73 (1980).

72. Gorski A, Podobinska I, Nowaczyk M, KorczakKowalska G: Immunomodulatory effects of thymic factor (TFX) on the interactions between T- and Bcells and their sensitivity to immunosuppressive agents, in Byron N A, Hobbs $\mathrm{J}$ R (eds): Thymic Factor Therapy, pp. 103-112. New York, Raven Press (1984).
73. Skotnicki A B, Aleksandrowicz J, Lisiewicz J: Effect of the calf thymus extract on immunologic reactivity in patients with hypogammaglobulinaemia. Boll Ist Sieroter Milan 54, 500 (1975).

74. Romanski B, Montowska L, Zbikowska-Gotz M, Staszynska M: Treatment of selected patients with acquired immune deficiency using preparation TFXPolfa. Pol Tyg Lek 40, 1139 (1985).

75. Moniuszko T, Blasiak J, Chyrek-Borowska S: The results of immunomodulatory treatment in patients with endogenous bronchial asthma, in ChyrekBorowska S (ed): Immunomodulation (Bialowieza), p. 48. Polish Immunological Society (1987).

76. Siwinska-Golebiowska H, Smogorzewska E, Domanska J: The in vitro and in vivo immunomodulatory effects of Levamisole and TFX in children with primary and secondary immunodeficiency states, in Chyrek-Borowska S (ed): Immunomodulation (Bialowieza), p. 52. Polish Immunological Society (1987).

77. Skotnicki A B, Dabrowska-Bernstein B K, Dabrowski M P: Perspectives in human humoral thymotherapy and the existing clinical experience with TFX-Polfa, in Kouttab N (ed): Thymic Hormones: Immunological Mechanisms and Therapeutic Action. New York, Marcel Dekker, in press.

78. Skotnicki A B: Influence of immunomodulators in interleukin 2 production. Przeg Lek 42, 573 (1985).

79. Skotnicki A B: The role of interleukin 2 in immune response. Immun Pol 12, 183 (1987).

80. Skotnicki A B: Thymic hormones and lymphokines. Drugs Today, in press.

81. Kornaszewski W, Lurhuma K, Skotnicki A B: The immunoprophylaxis and/or immunotherapy with thymic hormones in HIV-seropositive asymptomatic subjects and in AIDS patients, in 2nd International Symposium on AIDS and Associated Cancers in Africa, Naples, Oct. 7-9, Abstracts, p. 15 (1987). 